\title{
Shock enhancement of cellular structures under impact loading: Part I Experiments
}

\author{
I. Elnasri, ${ }^{1}$ S. Pattofatto, ${ }^{1}$ H. Zhao, ${ }^{1 *}$ H. Tsitsiris, ${ }^{1}$ F. Hild ${ }^{1}$ and Y. Girard ${ }^{2}$ \\ ${ }^{1}$ Laboratoire de Mécanique et Technologie (LMT-Cachan) \\ ENS-Cachan/CNRS-UMR8535/Université Paris 6 \\ 61 avenue du Président Wilson, F-94235 Cachan Cedex, France \\ ${ }^{2}$ EADS-CCR Suresnes, 12 bis rue Pasteur \\ F-92152 Suresnes Cedex, France
}

\begin{abstract}
This paper aims at showing experimental proof of the existence of a shock front in cellular structures under impact loading, especially at low critical impact velocities around $50 \mathrm{~m} / \mathrm{s}$. First, an original testing procedure using a large diameter Nylon Hopkinson bar is introduced. With this large diameter soft Hopkinson bar, tests under two different configurations (pressure bar behind / ahead of the supposed shock front) at the same impact speed are used to obtain the force / time histories behind and ahead of the assumed shock front within the cellular material specimen.

Stress jumps (up to $60 \%$ of initial stress level) as well as shock front speed are measured for tests at $55 \mathrm{~m} / \mathrm{s}$ on Alporas foams and nickel hollow sphere agglomerates, whereas no significant shock enhancement is observed for Cymat foams and 5056 aluminium honeycombs. The corresponding rate sensitivity of the studied cellular structures is also measured and it is proven that it is not responsible for the sharp strength enhancement.

A photomechanical measurement of the shock front speed is also proposed to obtain a direct experimental proof. The displacement and strain fields during the test are obtained by correlating images shot with a high speed camera. The strain field measurements at different times show that the shock front discontinuity propagates and allows for the measurement of the propagation velocity.
\end{abstract}

All the experimental evidences enable us to confirm the existence of a shock front enhancement even at quite low impact velocities for a number of studied materials.

*Corresponding author: zhao@lmt.ens-cachan.fr 


\section{Introduction}

Impact behaviour of metallic cellular materials (e.g., honeycomb, foam, hollow sphere agglomerate) has gained an increasing research interest because such materials are involved in the energy absorption design in automotive and aeronautical applications.

A large number of experimental, numerical and analytical studies on the behaviour of cellular materials under quasi-static loading have been reported in the past decades. The most important feature is that the behaviour of a cellular material can be derived from the base material (cell wall material) and its relative density with a reasonable accuracy (Gibson and Ashby, 1988). The microstructure as well as the crushing mechanism has only a limited effect compared to the relative density of the cellular materials. This result is only a general trend and no localisation phenomena as shown in transverse crushing of honeycomb (Klintworth and Stronge, 1988) are considered.

Under relative low impact loading, many experimental studies on various cellular materials, mainly using Split Hopkinson pressure bars or derived techniques, have been reported. For example, Goldsmith and Sackman (1992) reported some experimental work on out-of-plane crushing of honeycombs and found a stress increase by up to $50 \%$ with respect to static results. Wu and Jiang (1997), Zhao and Gary (1998) have also found a significant enhancement of out-of-plane crushing behaviour of aluminium honeycombs. For more isotropic metallic cellular materials such as aluminium foams, Deshpande and Fleck (2000) used a standard split Hopkinson pressure bar (SHPB) set-up (diameter: $12.7 \mathrm{~mm}$ ) with a polymeric output bar to test Alulight and Duocel foams. Results were obtained with considerable scatter and no rate sensitivity was observed. Mukai et al. (1999) have investigated Alporas foams using also a standard SHPB arrangement and reported significant rate sensitivity. Dannemann \& Lankford (2000) also reported rate sensitive results for Alporas foam. All these results seem to show that the rate sensitivity of cellular materials is more or less limited at moderate impact velocity $(<40 \mathrm{~m} / \mathrm{s})$. Such rate sensitivity depends strongly on the microstructure and deformation mechanism. For example, it is shown that the lateral inertia effect in the impact crushing of honeycomb is responsible for its rate sensitivity (Zhao and Abdennadher, 2004) whereas crushing by cell wall cracking for Cymat aluminium foam is rate insensitive (Zhao et al., 2005).

Under relative high impact speed, a very strong strength enhancement was originally observed by Reid and Peng (1997) for woods. They used a gas gun to fire wood at a velocity 
up to $250 \mathrm{~m} / \mathrm{s}$ to strike a target at the rear of which a Hopkinson bar is instrumented. They proposed a Rigid Perfectly Plastic Locking (RPPL) shock model to explain the measured strong enhancement. A number of experimental and numerical works confirm this shock enhancement. Tan et al. $(2002,2005)$ reported shock effect on Cymat foam and they believed that there exists a critical velocity $(44 \mathrm{~m} / \mathrm{s}$ to $108 \mathrm{~m} / \mathrm{s}$ ) under which such shock effect is not significant. Lopatnikov et al. (2003) showed shock enhancement of IFAM aluminium foams (up to $200 \mathrm{~m} / \mathrm{s}$ ) using a so-called Taylor cylinder-Hopkinson bar impact test and numerical analyses were also performed to simulate those tests. Lopatnikov et al. (2004) also reported plate impact tests of these foams at higher impact speed $(1000 \mathrm{~m} / \mathrm{s})$. Rodford et al. (2005) reported test results (up to $500 \mathrm{~m} / \mathrm{s}$ ) on Alporas foams using a similar Hopkinson pressure bar technique.

Even though this shock enhancement seems to be accepted for very high impact speeds, it is not so clear for rather low impact speeds around the so-called critical velocity $(\sim 50 \mathrm{~m} / \mathrm{s})$. There is no convincing experimental proof because the only available experimental observation is the force measurement behind the supposed shock front. In addition, the knowledge about this so-called shock enhancement is not complete because there is still a lack of experimental results on many known cellular materials of different microstructures (namely, different foams, hollow spheres). It is not known whether the microstructure and the crushing mode will have an influence on this enhancement as it is the case for rate sensitivity at low impact loading. Therefore, new and more complete experimental results are needed to investigate the aforementioned issues to better understand the fundamental aspects of enhancement.

The present paper aims at finding experimental proofs of the existence of this shock front, especially at impact speeds around the so-called critical velocity. A new experimental procedure is considered. It consists in testing cellular materials in two distinct configurations, namely, cellular samples acting as projectile or as target. It allows for an indirect measurement of the force / time histories ahead of and behind the shock front.

Testing results around $55 \mathrm{~m} / \mathrm{s}$ for a number of cellular materials of various microstructures (5056 aluminium honeycombs, Cymat and Alporas aluminium foams, as well as nickel hollow sphere agglomerates) are presented. A significant shock enhancement at such velocity is observed for the tested Alporas foam and nickel hollow spheres. The force / time histories behind and ahead of the shock front allow for a quantitative estimation of the stress jump and the shock front speed. Last, another and more direct experimental proof of the shock front is given by the measurement of strain jump during the tests. This is 
made possible by using a high speed camera and image correlation. It allows for a more accurate shock front speed measurement.

\section{Cellular materials and shock enhancement effect}

Foam-like cellular materials exhibit in general a small elastic response, a long quasiperfectly plastic regime corresponding to the successive crushing of cell walls until a socalled locking strain where compaction of crushed cell walls starts. At this large strain, stress goes up sharply and approaches asymptotically the elastic response of the cell wall material as shown in Figure 1 for an Alporas foam of mass density $245 \mathrm{~kg} / \mathrm{m}^{3}$.

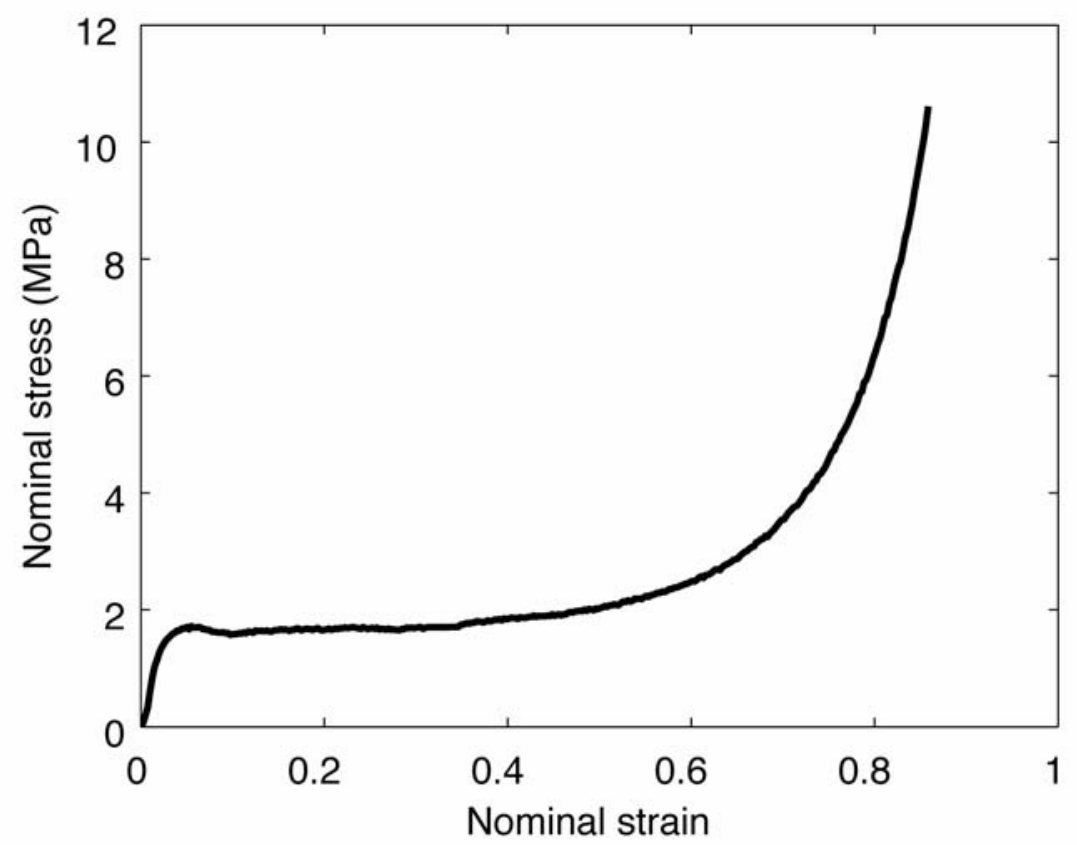

Figure 1. Typical stress-strain relation of a foam-like material (Alporas, $245 \mathrm{~kg} / \mathrm{m}^{3}$ )

The concave part of the stress-strain relationship due to densification may lead to the inception of the shock front. A concave stress-strain relationship yields a higher nominal wave speed with the increase of nominal strain levels within the assumption of common elasto-plastic wave propagation theories. Therefore, if the impact loading is strong enough to reach densification from which the concave part is engaged, a shock front is created. Let us recall briefly what happens if a shock front is created. Figure 2 shows a foam-like uniaxial specimen within which a shock front propagates at a velocity $U$. The density, particle velocity 
and stress ahead of and behind this shock front are respectively denoted by $\left(\rho_{0}, v_{0}, \sigma_{0}\right)$ and $\left(\rho_{1}\right.$, $\left.v_{1}, \sigma_{1}\right)$.

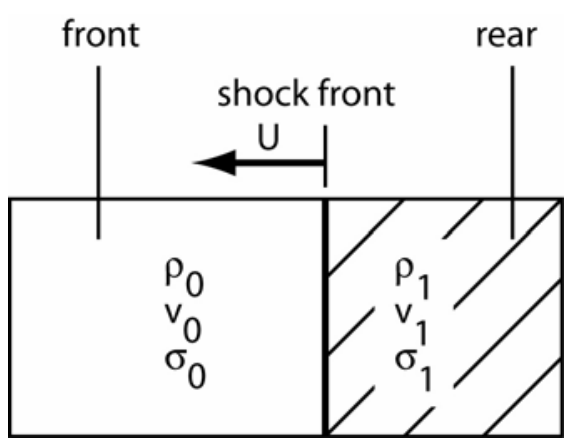

Figure 2. Shock front within a foam-like specimen

From the Rankine-Hugoniot jump conditions through this shock front, the conservation of mass, and kinematic quantities read

$$
\begin{gathered}
\rho_{1}\left(U-v_{1}\right)=\rho_{0}\left(U-v_{0}\right) \\
\sigma_{1}-\sigma_{0}=\rho_{0}\left(U-v_{0}\right)\left(v_{1}-v_{0}\right)
\end{gathered}
$$

Such a shock wave concept was used to explain the huge strength enhancement experimentally observed under high speed impact. Reid and Peng (1997) have proposed a Rigid Perfectly Plastic Locking (RPPL) simplification of the foam-like material using two parameters, namely the plastic flow stress $\sigma_{\mathrm{y}}$ and the rigid locking strain $\varepsilon_{\text {lock }}$ (Figure 3 ).

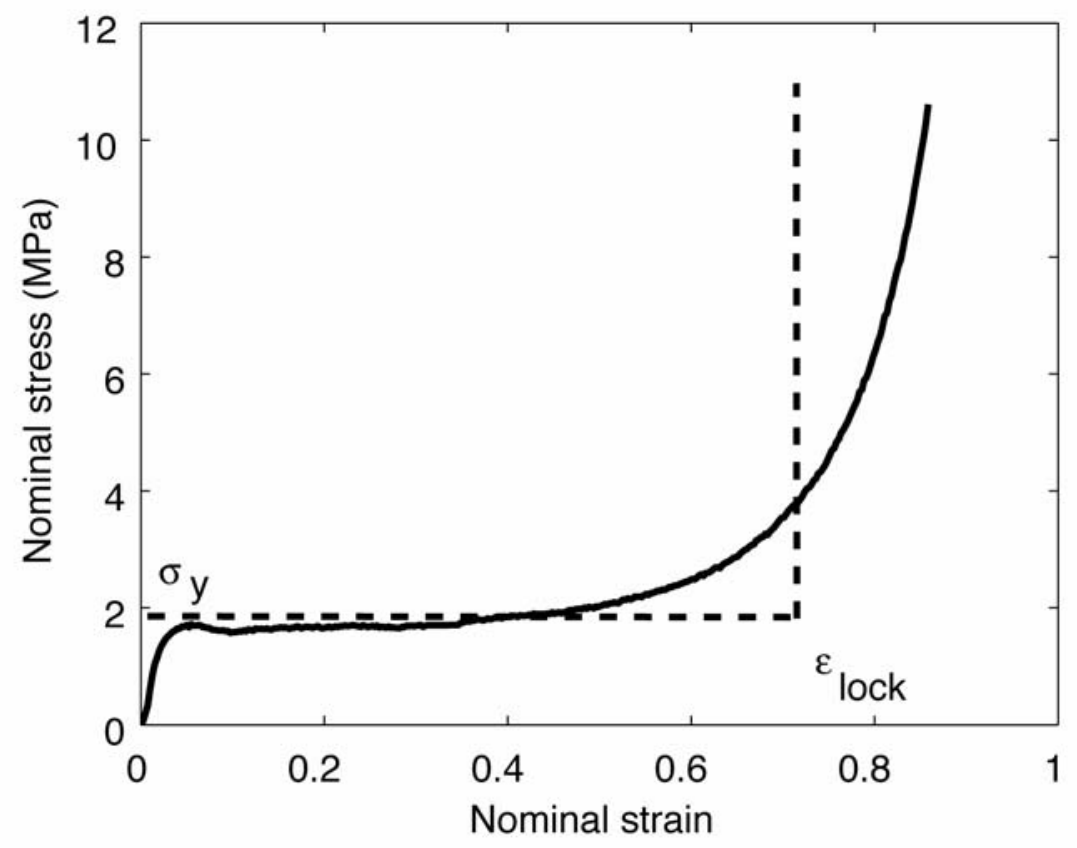

Figure 3. Simplified Rigid Perfectly Plastic Locking model 
It leads to the following formula to calculate the stress jump (see Appendix for details)

$$
\sigma_{1}-\sigma_{y}=\frac{\rho_{0} V_{\text {impact }}^{2}}{\varepsilon_{\text {lock }}}
$$

where $\mathrm{V}_{\text {impact }}$ denotes the constant impact velocity, $\rho_{0}$ the initial mass density and $\varepsilon_{\text {lock }}$ the locking strain.

\section{Testing set-up using a large diameter Nylon}

\section{Hopkinson bar}

In the previous experimental studies on the shock effect, most of the tests were performed by launching a foam specimen to a measuring target often instrumented by a rear Hopkinson bar. In such a configuration, only the stress and particle velocity behind the shock front are measured. The shock front speed and the stress jump across the shock front cannot be estimated. In order to overcome these difficulties, a new testing method is designed to provide desired experimental proofs of the existence of such a shock front formation.

\subsection{Experimental architecture}

The proposed experimental setup is also based on the use of Hopkinson pressure bar. A 60-mm in diameter and 6-m long Nylon Hopkinson bar is used as measuring device and a gas gun with a $70 \mathrm{~mm}$ inner diameter barrel is used to launch a projectile. Two testing configurations are considered, namely, one is to cement the sample on the Hopkinson bar and to launch the bullet to strike the sample (Figure 4a). Another possibility is to cement the sample to the end of a small flat ended Nylon bullet. The sample and bullet are fired at about $60 \mathrm{~m} / \mathrm{s}$ to strike the 60-mm Nylon Hopkinson bar (Figure 4b).

To ensure perfect reversibility, the bullet used in the two configurations is the same. As the driving mass (here the mass of the bullet) has an influence on the shock front (Tan et al. 2005), in this study, the bullet mass is chosen to be important enough so that the deceleration of the bullet during the test is negligible at the studied impact velocity around $50 \mathrm{~m} / \mathrm{s}$. It enables one to eliminate the driving mass influence from this study. 


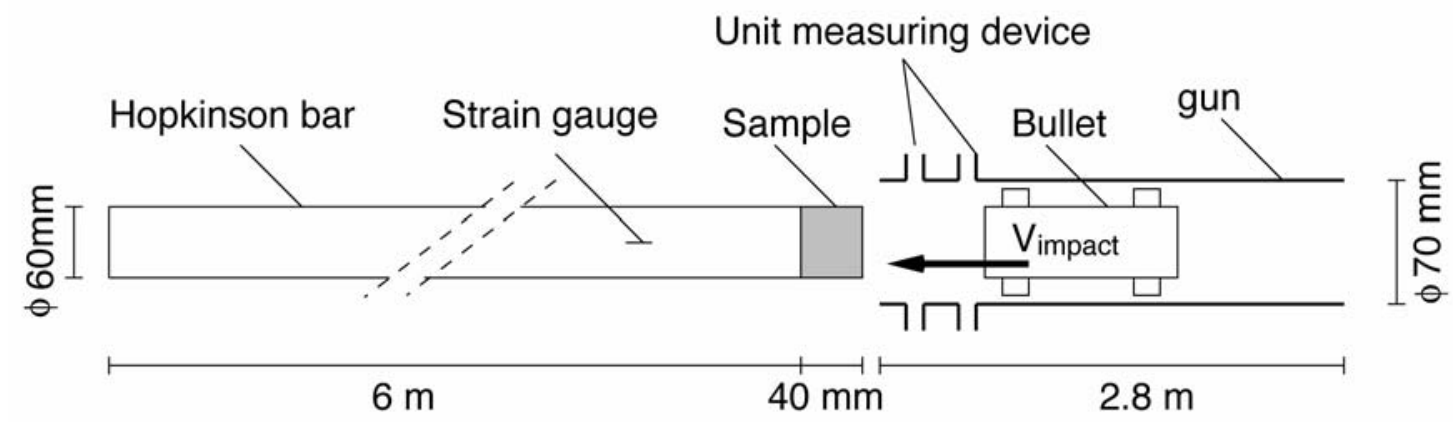

a) Configuration 1: direct impact Hopkinson bar test

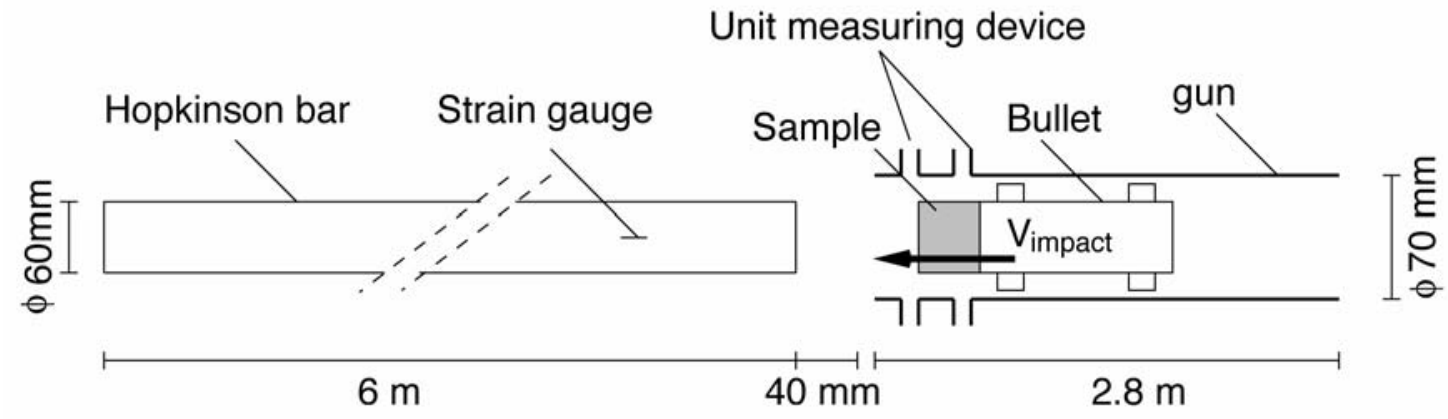

b) Configuration 2: Hopkinson bar-Taylor test

Figure 4: Two experimental configurations

For configuration 1, the shock wave propagates from the impact side (projectile side) to the pressure bar so that the pressure bar measures the stress ahead of the shock front (case 1, Figure 5). On the other hand, if the sample is cemented on the projectile and the test is performed at the same impact velocity, the shock front propagates from the pressure bar side to the projectile side so that the pressure bar measures the stress behind the shock front (case 2, Figure 5). The difference between these two stress profiles determines the stress jump (Eqn. (3)). 


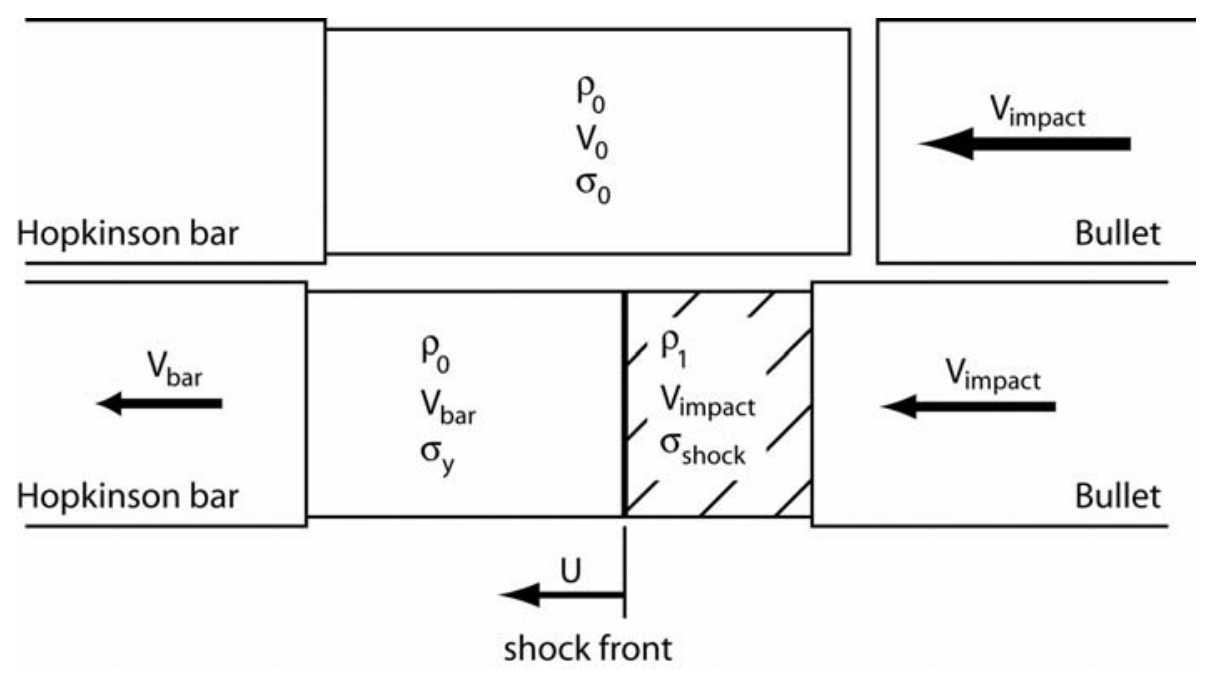

a) Case 1

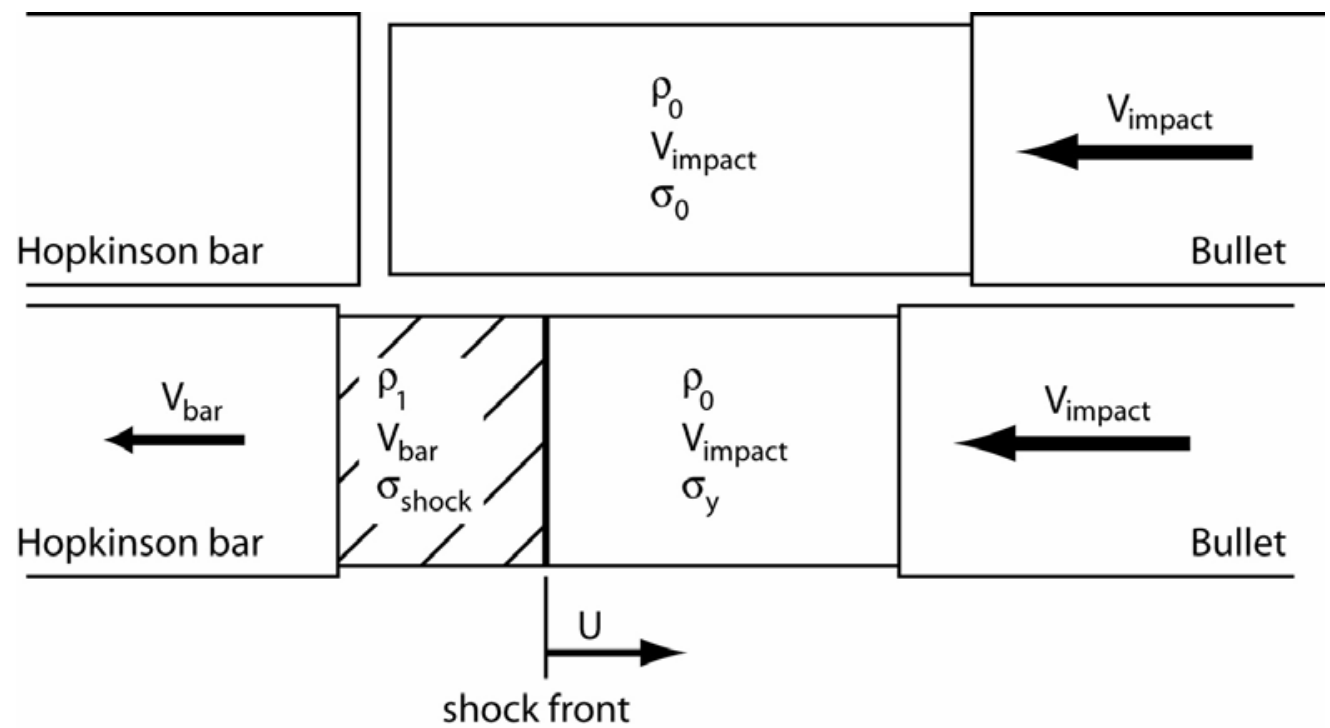

b) Case 2

Figure 5. Depiction of the shock front in the two different testing configurations

If initial elasticity is neglected, a simple uniaxial analysis of the two testing configurations is written as follows:

- Case 1: Direct impact Hopkinson bar test.

For the Hopkinson bar impact test configuration, ahead of and behind the shock front, the following conditions are satisfied

$$
\begin{array}{ll}
\rho_{0} & \rho_{1}=\frac{\rho_{0}}{1-\varepsilon_{\text {shock }}} \\
\sigma_{0}=\sigma_{\mathrm{y}} & \sigma_{1}=\sigma_{\text {shock }} \\
\mathrm{v}_{0}=\mathrm{v}_{\text {bar }} & \mathrm{v}_{1}=\mathrm{V}_{\text {impact }}-\frac{\mathrm{S}_{\mathrm{b}} \sigma_{\text {shock }}}{\mathrm{m}_{\text {projectile }}} \mathrm{t} \approx \mathrm{V}_{\text {impact }}
\end{array}
$$


where $v_{1}$ is calculated from the initial impact velocity $V_{\text {impact }}$ constantly decelerated by the foam resistance. The particle velocity ahead of the shock front is related to the yield stress $\sigma_{\mathrm{y}}$ by

$$
\mathrm{v}_{0}=\mathrm{v}_{\mathrm{bar}}=\frac{\sigma_{\mathrm{y}}}{\rho_{\mathrm{b}} \mathrm{C}_{\mathrm{b}}}
$$

where $\rho_{b}$ and $C_{b}$ are respectively the mass density of and the wave speed in the Hopkinson bar. The shock stress $\sigma_{\text {shock }}$ is also related to the shock strain $\varepsilon_{\text {shock }}$ using the constitutive law of the studied material

$$
\sigma_{\text {shock }}=\mathrm{f}\left(\varepsilon_{\text {shock }}\right)
$$

- Case 2: Hopkinson bar-Taylor test.

For the second test configuration, ahead of and behind the shock front, the following relationships hold

$$
\begin{array}{ll}
\rho_{0} & \rho_{1}=\frac{\rho_{0}}{1-\varepsilon_{\text {shock }}} \\
\sigma_{0}=\sigma_{\mathrm{y}} & \sigma_{1}=\sigma_{\text {shock }} \\
\mathrm{v}_{0}=\mathrm{V}_{\text {impact }} & \mathrm{v}_{1}=\mathrm{V}_{\text {bar }}
\end{array}
$$

From the jump relation of the elastic wave in the Hopkinson bar, the particle velocity is proportional to the shock stress $\sigma_{\text {shock }}$

$$
\mathrm{v}_{1}=\mathrm{v}_{\mathrm{bar}}=\frac{\sigma_{\text {shock }}}{\rho_{\mathrm{b}} \mathrm{C}_{\mathrm{b}}}
$$

Equations (1-2, 4-6) for case 1 or $(1-2,6-8)$ for case 2 allow for the calculation of the shock stress $\sigma_{\text {shock }}$ as well as the shock front velocity U. It is worth noting that the shock strain $\varepsilon_{\text {shock }}$ depends on the constitutive law and impact velocity. An explicit formula is only possible if a constitutive model is chosen.

If the RPPL simplification of the stress-strain relation is assumed (Figure 3), by neglecting the velocity of the Hopkinson bar, which remains small, a simple expression is obtained for the two configurations in the same way as Eqn. (A3) of the Appendix:

- Case 1

$$
U=\frac{V_{\text {impact }}}{\varepsilon_{\text {lock }}} \text { and } \sigma_{\text {shock }}-\sigma_{y}=\frac{\rho_{0} V_{\text {impact }}^{2}}{\varepsilon_{\text {lock }}}
$$


- Case 2

$$
U=-\frac{1-\varepsilon_{\text {lock }}}{\varepsilon_{\text {lock }}} V_{\text {impact }} \text { and } \sigma_{\text {shock }}-\sigma_{y}=\frac{\rho_{0} V_{\text {impact }}^{2}}{\varepsilon_{\text {lock }}}
$$

\subsection{Measurement accuracy of the proposed setup}

The main measurement feature of these two testing configurations is the use of a large diameter Nylon Hopkinson bar. It is important to use such bars because the impact tests on metallic cellular materials using a SHPB have two major drawbacks from an experimental point of view. On the one hand, a large scatter arises due to the small size ratio between sample and cells. To overcome this difficulty, a large diameter pressure bar is necessary to study a larger specimen. On the other hand, small signal levels are expected due to the low strength of cellular materials, which leads to a low signal/ noise ratio. Therefore, large diameter and soft Nylon pressure bars are used. For this reason, the experimental results obtained with such a device are expected to be more accurate than previously published works in the open literature.

Since the conventional Hopkinson pressure bar analysis is based on the onedimensional wave propagation assumption (Hopkinson, 1914; Kolsky, 1949), the stress and the particle velocity associated with a single wave are then proportional to the associated strain measured by gauges for a single wave. The crushing force $F(t)$ and velocity $v(t)$ time histories are then calculated as

$$
\begin{aligned}
& F(t)=S_{b} E_{b} \varepsilon(t) \\
& v(t)=C_{b} \varepsilon(t)
\end{aligned}
$$

where $S_{b}, E_{b}$ and $C_{b}$ are respectively the cross sectional area, the Young's modulus and the elastic wave speed of the pressure bar.

However, such a theory cannot describe the possible wave dispersion effect in a viscoelastic bars (Zhao and Gary, 1995) that may introduce some bias in the virtual shift from the measuring point to the bar-specimen interface in time and space. The correction of this dispersion effect on the basis of a generalised Pochhammer's wave propagation theory is systematically performed in the data processing stage of this wave shift (Davies, 1948; Zhao and Gary, 1996). 


\section{Testing results}

\subsection{Studied materials and their behaviour under quasi-static loading}

Four materials of different microstructures are investigated in this study, namely, aluminium Alporas and Cymat foam, 5052 aluminium honeycomb, nickel Ateca hollow spheres. Figure 6 shows cylindrical specimens made of these four materials, the dimensions of which are a diameter of $60 \mathrm{~mm}$ and a length of $40 \mathrm{~mm}$. The average density of these materials is given in Table 1.



(a)

(b)

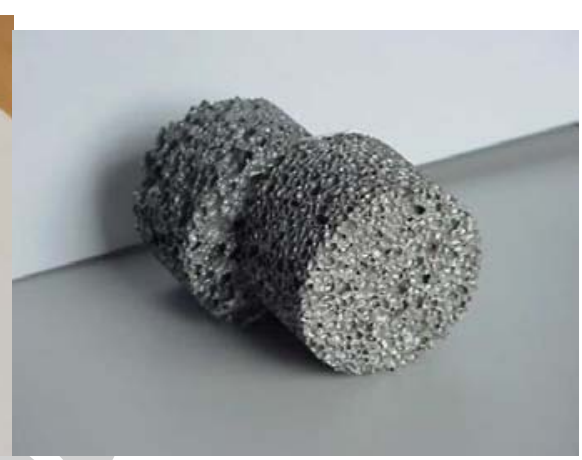

(c)

Figure 6. Honeycomb and Cymat foam (a), Hollow spheres (b), Alporas foam (c) specimens (diameter: $60 \mathrm{~mm}$, length: $40 \mathrm{~mm}$ )

Table 1 . Initial density of the tested materials $\left(\mathrm{kg} / \mathrm{m}^{3}\right)$

\begin{tabular}{cccc}
\hline Alporas foam & Hollow spheres & Cymat foam & Honeycomb \\
245 & 219 & 235 & 38 \\
\hline
\end{tabular}

The microstructure of these materials is different. If honeycomb is anisotropic and only its properties in the principal direction are of interest here (i.e., that of hexagonal cell column axis), the others are more or less isotropic. The crushing mode of these materials is also different. The Cymat foam is brittle and the crushing mechanism is cracking of the cell wall, whereas Alporas foam, hollow spheres, and honeycombs are much more ductile and exhibit a mode of successive folding of the cell walls. Typical nominal stress-strain curves under quasistatic loading are shown in Figure 7. 


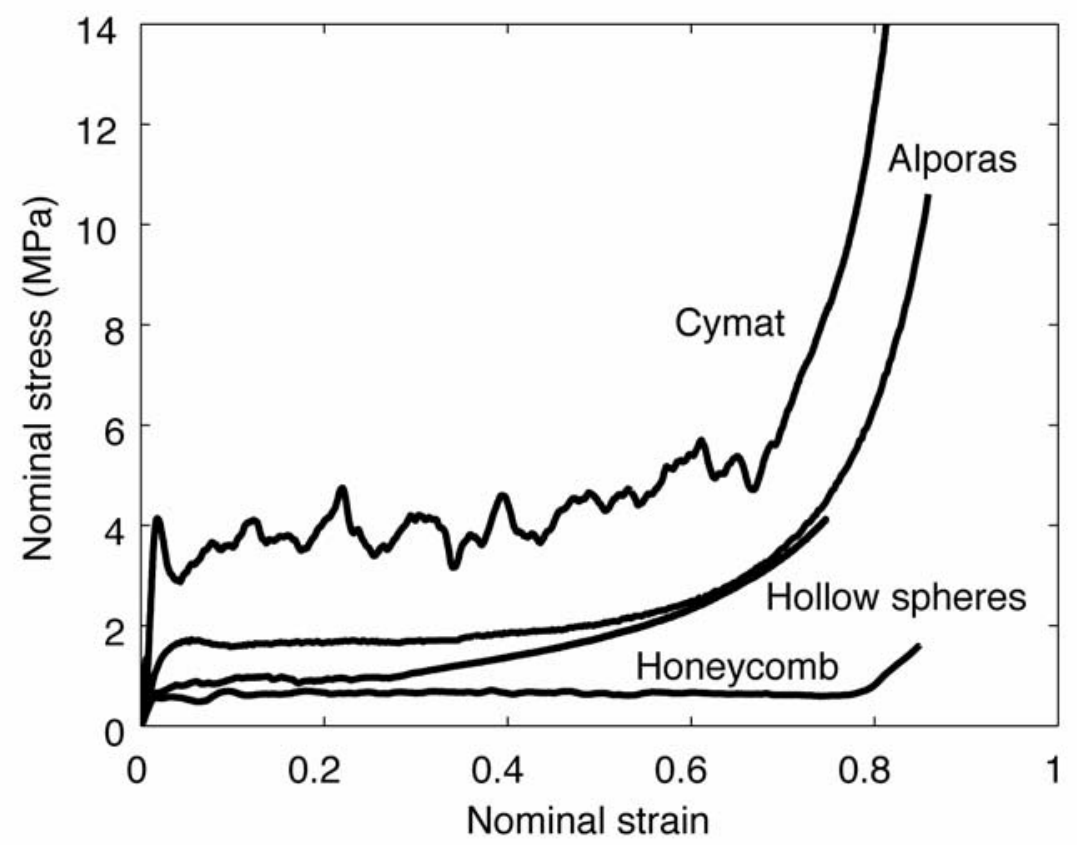

Figure 7. Typical quasi-static stress / strain response of the tested materials

\subsection{Shock enhancement observed for Alporas foam and Ateca hollow spheres}

Figure 8 shows the force / time histories observed in the two different configurations for Alporas foam at about $55 \mathrm{~m} / \mathrm{s}$. The stress ahead of the shock front (config. 1) is significantly different from the stress behind this front (config. 2). The shock stress jump is measured as the difference between the two curves at the early plateau stage. From the force / time histories, the shock front propagation speed is also estimated. The time difference $\Delta \mathrm{t}$ before the intersection of the two force responses represents the time for this shock front to travel through the residual length of the specimen after shock front inception and it gives a first order estimate of the shock front speed. 


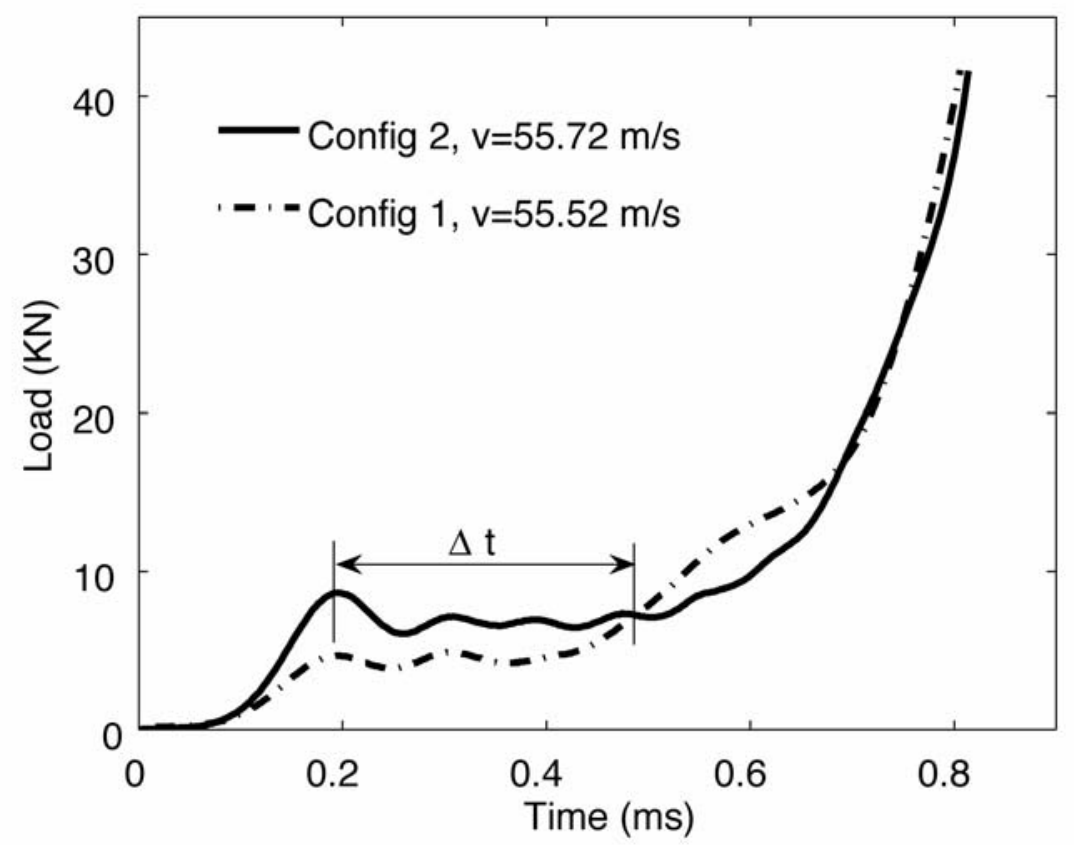

Figure 8. Force profile ahead of (config. 1) and behind (config. 2) the shock front for Alporas foam

Different tests performed on Alporas foam are summarized in Table 2 (noting that the enhancement shown in the table has been corrected for by the specimen density). It shows that the rate sensitivity (excluding shock enhancement) of Alporas foam is limited (config. 1). Therefore, the rate sensitivity of the foam cannot explain the enhancement measured under testing configuration 2 .

Table 2. Testing results for Alporas foam

\begin{tabular}{cccc}
\hline Test type & $\begin{array}{c}\text { Density } \\
\left(\mathrm{kg} / \mathrm{m}^{3}\right)\end{array}$ & $\begin{array}{c}\text { Impact speed } \\
(\mathrm{m} / \mathrm{s})\end{array}$ & $\begin{array}{c}\text { Yield stress } \\
(\mathrm{MPa})\end{array}$ \\
\hline Quasi-static & 245 & 0.00001 & 1.69 \\
Config. 1 & 255 & 19.17 & 2.15 \\
Config. 1 & 253 & 47.01 & 2.01 \\
Config. 1 & 233 & 55.2 & 1.83 \\
Config. 2 & 230 & 55.15 & 2.66 \\
\hline
\end{tabular}

Similar shock enhancement is observed for nickel hollow spheres by force/time histories of two different configurations at about $55 \mathrm{~m} / \mathrm{s}$ (Figure 9). 


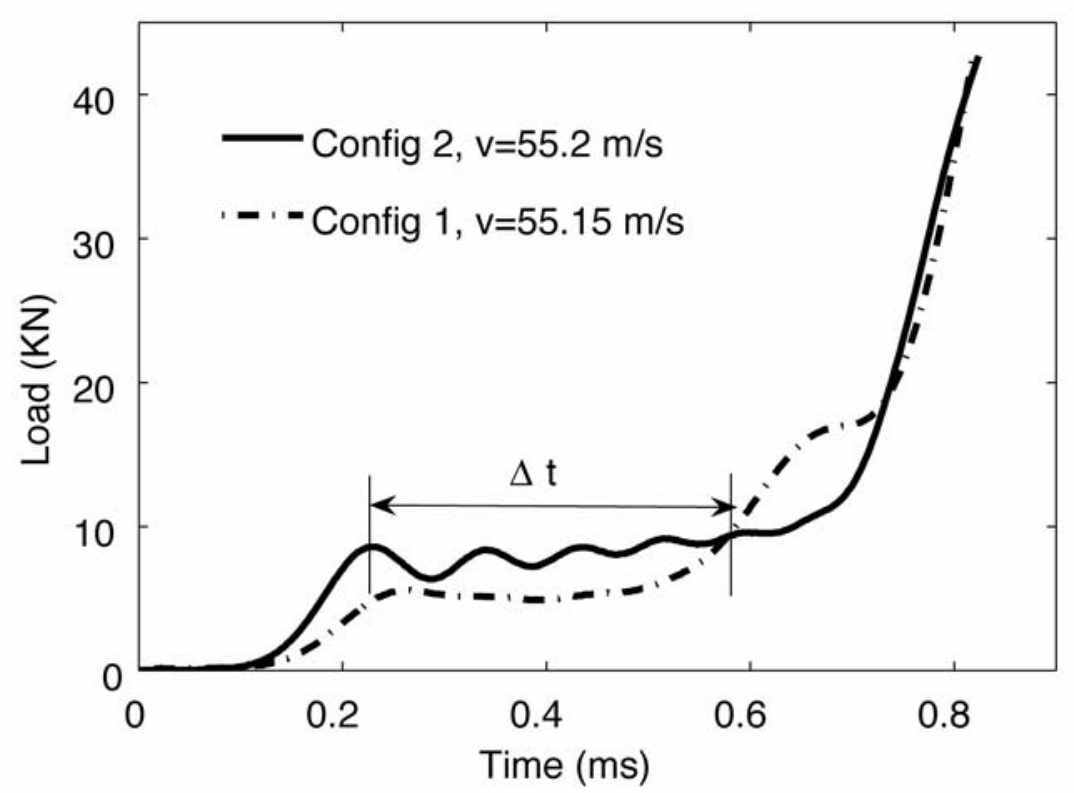

Figure 9. Force profile ahead of (config. 1) and behind (config. 2) the shock front for nickel hollow spheres

Testing results for these two materials at various impact speed are plotted together to give a general view in Figure 10. Correction of raw testing results is performed to reduce the influence of the initial density of the tested samples (Gibson and Ashby, 1988). In the present paper, a correction of power 1.5 of the density factor (i.e., ratio between sample density and average density) is performed as usually carried out in the literature (Tan et al. 2005) for this type of materials. It is to be noted that such a power 1.5 density correction is rather arbitrary because it is based on the assumption of dominant cell wall bending mechanism (Gibson and Ashby, 1988). It could be a power around 1.25 when membrane deformation is dominant (Karagiozova et al., 2006). The corrected testing results show that the test in configuration 2 is fundamentally different from the tests in configuration 1 at the same impact velocity (Fig. $10)$. 


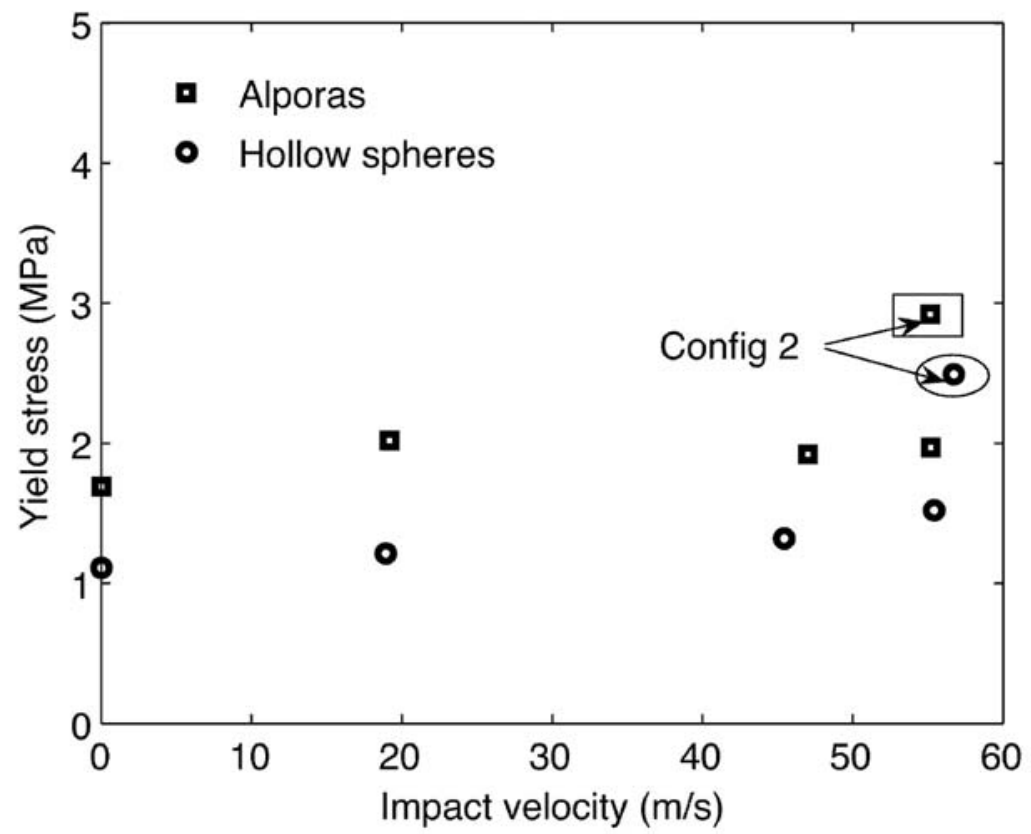

Figure 10. Summary of testing results for Alporas foam and nickel hollow spheres

\subsection{Observations for Cymat foam and Honeycombs}

No significant shock enhancement effect is observed for Cymat foams and honeycombs.

Figure 11 gives a summary of the testing results for the two materials.

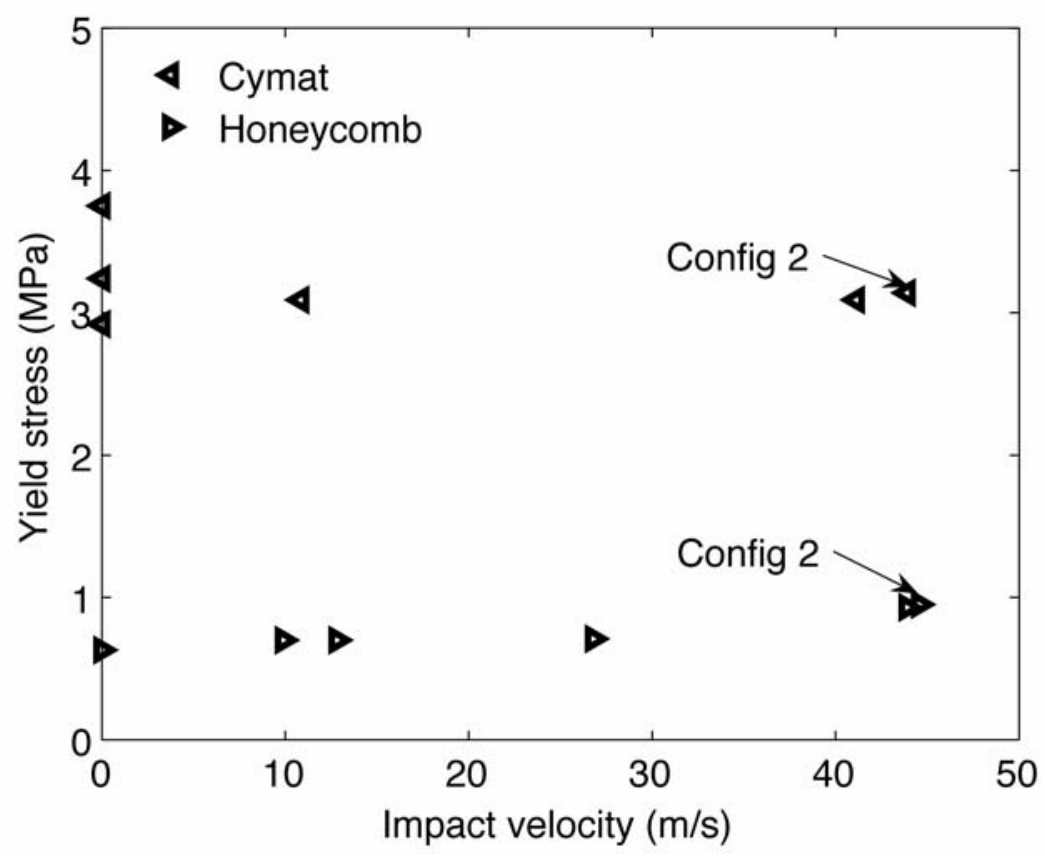

Figure 11. Summary of the testing results for honeycomb and Cymat foam 
The comparison of the measured force curves in the two configurations at an impact speed of about $45 \mathrm{~m} / \mathrm{s}$ is also given for Cymat foam (Figure 12a) and honeycomb (Figure 12b). The force jump behind and ahead of the supposed shock front is very small. Such a result indicates that the shock enhancement effect is negligible for these two materials at an impact velocity less than $45 \mathrm{~m} / \mathrm{s}$. Even if there exists a rate sensitivity of the tested honeycomb as shown in Figure 11, it is not due to shock enhancement. It is a rate sensitivity due to inertia effects in dynamic buckling of cell walls (Zhao and Abdennadher, 2004).

(a)
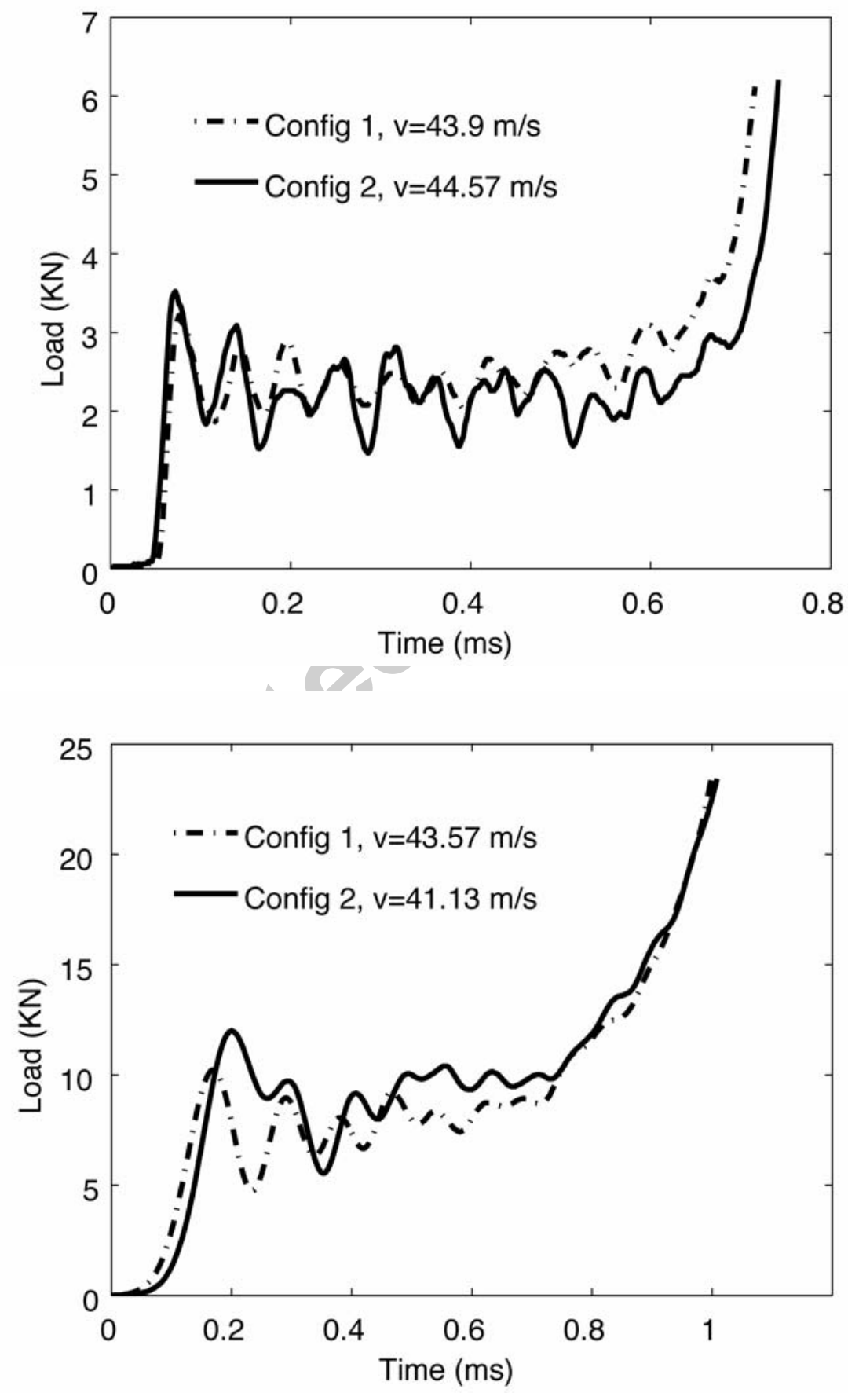
Figure 12. Force history ahead of (config. 1) and behind (config. 2) the shock front for honeycomb (a) and Cymat foam (b)

\subsection{Discussion}

An important property is the rate sensitivity of the studied materials. A summary of the flow stress for these materials under various testing velocities is given in Figure 13. Since only the results obtained with direct impact Hopkinson bar (config. 1) are plotted, the rate sensitivity shown excludes the possible strength enhancement due to shock waves.

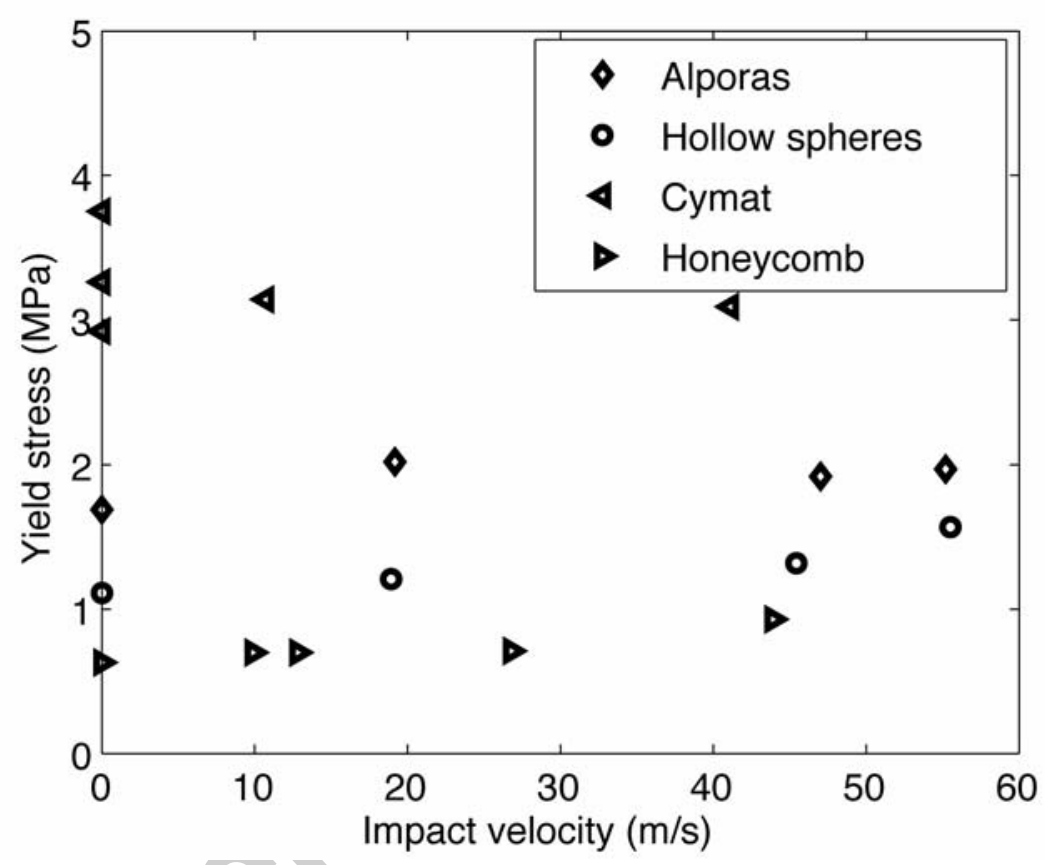

Figure 13. Rate sensitivity of the tested cellular materials

A limited rate sensitivity is found for Alporas foam and honeycomb, which is mainly due to inertia effects in the successive buckling of the cell walls (Zhao and Abdennadher, 2004; Han et al., 2005). Nickel hollow spheres exhibit also a rate sensitivity that is believed to be due to the rate sensitivity of the cell wall material. There is no clear sensitivity for Cymat foams, because the crushing mode is caused by cell wall cracking and the rate insensitivity of the cell wall material. This confirms that the stress difference between cases 1 and 2 is only due to shock enhancement. The average stress jump due to shock enhancement as well as the shock front speed for test around $50 \mathrm{~m} / \mathrm{s}$ is listed in Table 3 . 
Table 3. Shock enhancement and shock velocity estimates

\begin{tabular}{cccc}
\hline Material & $U(\mathrm{~m} / \mathrm{s})$ & $\left(\sigma_{\text {case } 2}-\sigma_{\text {case } 1}\right) / \sigma_{\text {case } 1}$ & $U(\mathrm{~m} / \mathrm{s})$ \\
\hline Alporas & 55 & $44 \%$ & 94 \\
Hollow spheres & 55 & $66 \%$ & 107 \\
Cymat foam & 43 & Not significant & - \\
Honeycomb & 44 & Not significant & - \\
\hline
\end{tabular}

\section{Measurement of shock front speed with a high-speed}

\section{camera and image correlation}

The experimental setup using a Nylon Hopkinson bar proposed above allows for an indirect determination of the stress jump across the shock front and the shock front propagation velocity. Such an analysis is based on the assumption that the specimens used in tests with the two different configurations behave identically. Since there is a scatter of behaviour for foam-like materials as shown in Figure 13, a direct measurement of the shock front within only one sample is desirable. It is performed by an optical measurement technique using a high-speed camera.

\subsection{Imaging setup and image correlation analysis}

Images are taken during a test on a cylindrical specimen in configuration 1 by using a high speed camera. The lighting of the specimen is obtained by two "cold-light" spotlights of $1000 \mathrm{~W}$ lux each. The record rate of the camera is chosen to be 20,000 frames per second (fps) to obtain a sufficient resolution $(256 \times 384$ pixels $)$ necessary for the following digital image correlation analysis. The shutter speed is chosen at $1 / 60,000 \mathrm{~s}$ so that the image is not blurred whereas the powerful lights ensure a correct contrast of the pictures (Figure 14). 


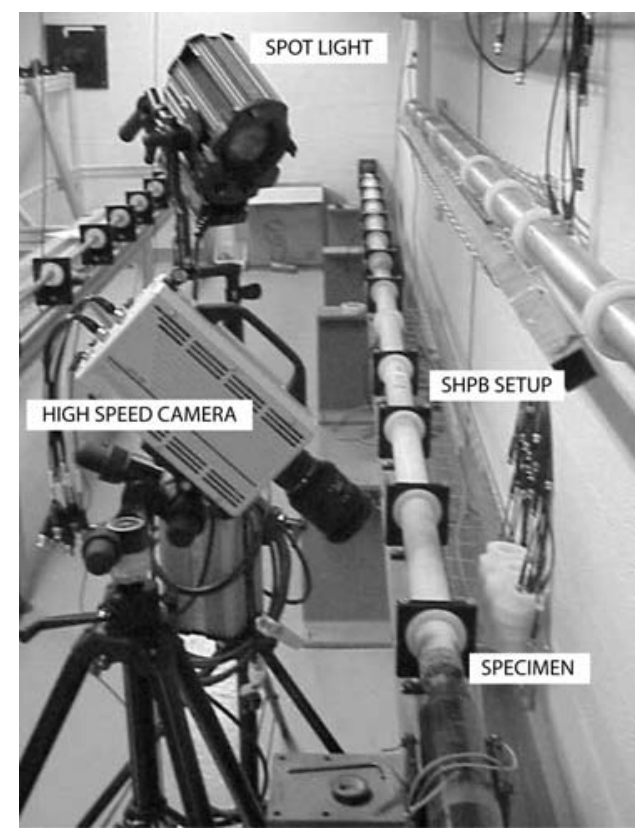

Figure 14. Experimental setup for image capture

Image captures of such kind of test have been reported before in the open literature (Radford et al., 2005, Nemat-Nasser et al; 2007). However, the images shown herein are used to perform a quantitative measurement of the displacement and strain fields. By considering an image sequence, the displacement fields between images are calculated by a "finite element" correlation algorithm (Besnard et al., 2006). A functional basis made of bilinear (i.e., P1) functions for each component of the displacement over square elements (i.e., Q4 elements in the language of the finite element method (Zienkievicz and Taylor, 1989)) is considered. By applying the linearised conservation of the optical flow, the displacement is obtained for each pair of pictures as a continuous Q4P1 field. Even though the displacement uncertainty is the lowest for large element sizes (Hild and Roux, 2006), the inhomogeneity of the displacement field prompts us to use small sizes. Sizes down to $6 \times 6$ pixels could be considered with a clear determination of the displacement. An uncertainty analysis consisting in artificially moving the reference picture (see, for instance, Figure 15a) by increments of 0.1 pixel in a $[0,1]$-pixel interval is performed. In the present case, average displacement uncertainties less than $5 \times 10^{-2}$ pixel were obtained for 8-bit pictures.

Figure 15 shows an example of raw images taken by the camera during a test on Alporas foam $\left(245 \mathrm{~kg} / \mathrm{m}^{3}\right)$ impacted at $47 \mathrm{~m} / \mathrm{s}$. No special preparation was needed. The natural texture of the sample is sufficient to capture displacements. An additional difficulty for the use of image correlation on foam-like specimens is the collapse of cells during compaction, which induces an important distortion of the texture. Even if a small window size 
is used to limit the affected range of a largely distorted region, it is not possible to calculate the displacement field for all recorded images. For the presented test on Alporas foam, 10 images were processed up to a nominal strain of about $40 \%$. In Figure 15b, the deformed meshes obtained by image correlation are presented.

Reference picture

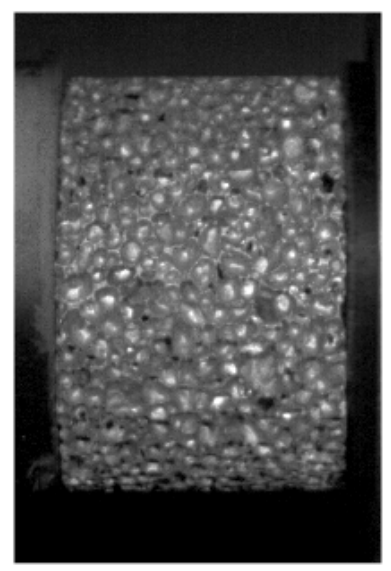

Image 2
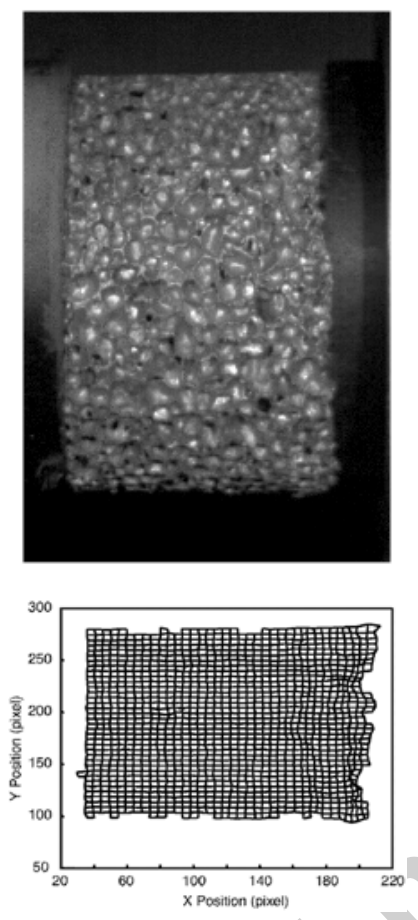

Image 4
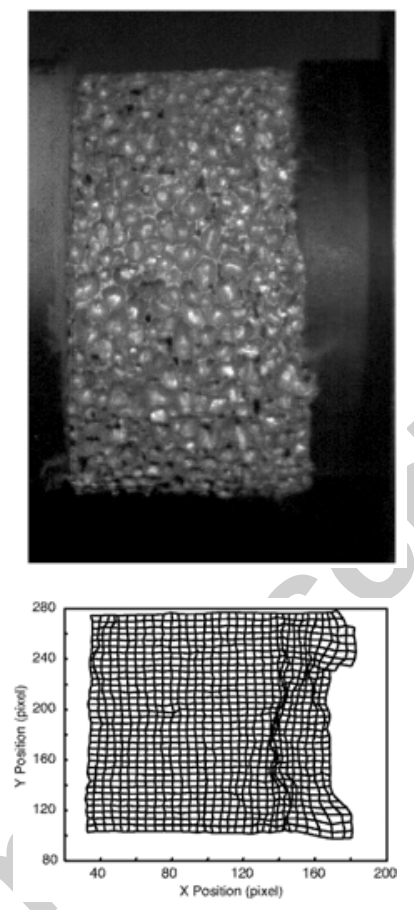

Image 6
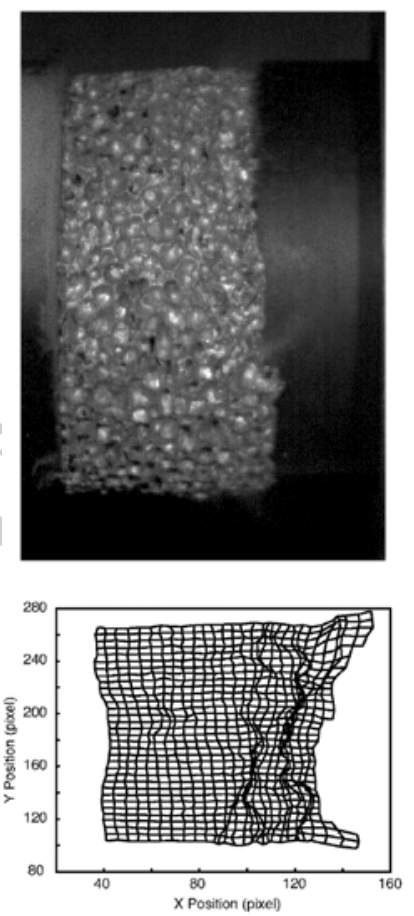

Figure 15. Raw images taken by the camera. Impact velocity of $47 \mathrm{~m} / \mathrm{s}$, acquisition rate: 20,000 fps. Corresponding deformed mesh calculated with a Q4P1 correlation algorithm.

When only one camera is used, out-of-plane displacements bias the estimates of inplane components. However, with the present correlation parameters (i.e., elements of size $6 \times 6$ pixels), it can be shown that the displacement uncertainty is such that the effect of outof-plane displacements remains less than the strain uncertainty. Furthermore, the Poisson's ratio of this type of material is vanishingly small. Therefore, the out-of-plane displacements remain small. Because of the sample geometry, only longitudinal displacement and strain components are used in the following analysis.

\subsection{Simplified analysis for the shock front speed calculation}

With the deformed meshes shown in Figure 15b, it is straightforward to calculate the corresponding strain fields. The strain component in the direction perpendicular to the cylinder axis has to be corrected for. The strain component along the cylinder axis is not 
affected by the correction. On the basis of this strain field, a quantitative estimation of the shock front velocity is obtained as follows. The mean value of the nominal strain is calculated for each longitudinal position. With this procedure, the strain field is converted into a uniaxial mean strain variation.

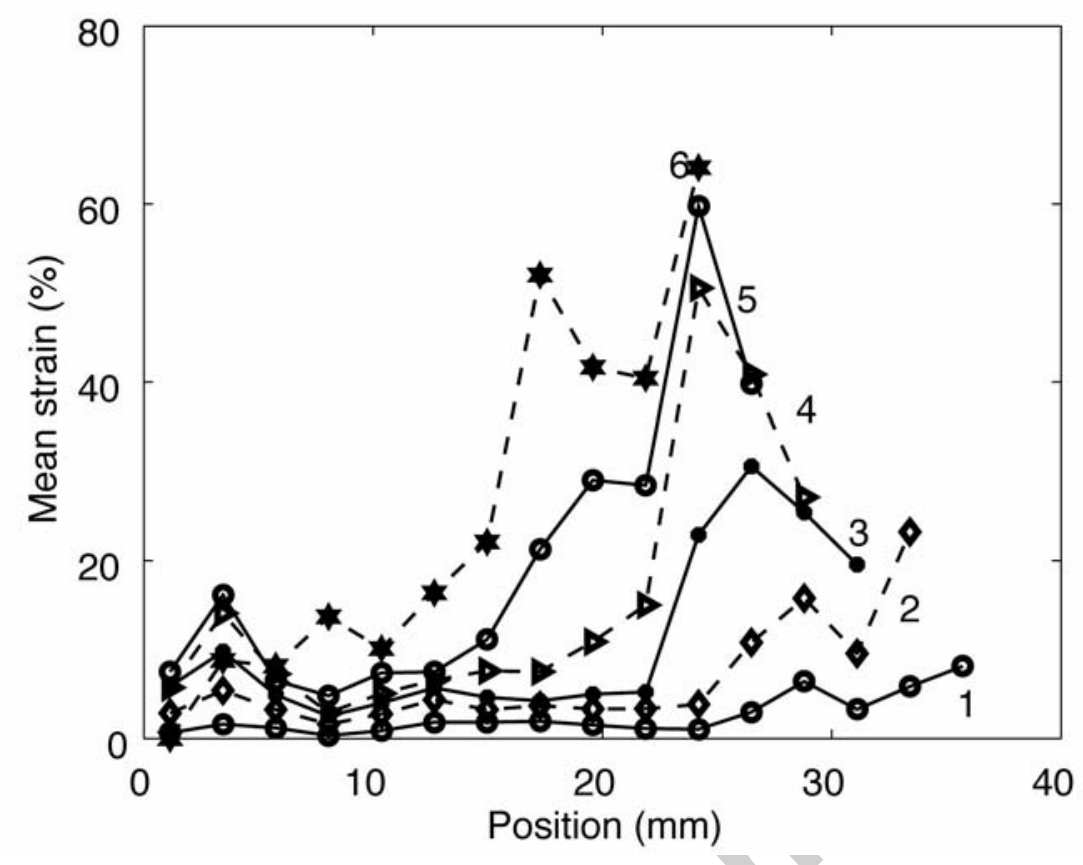

(a)

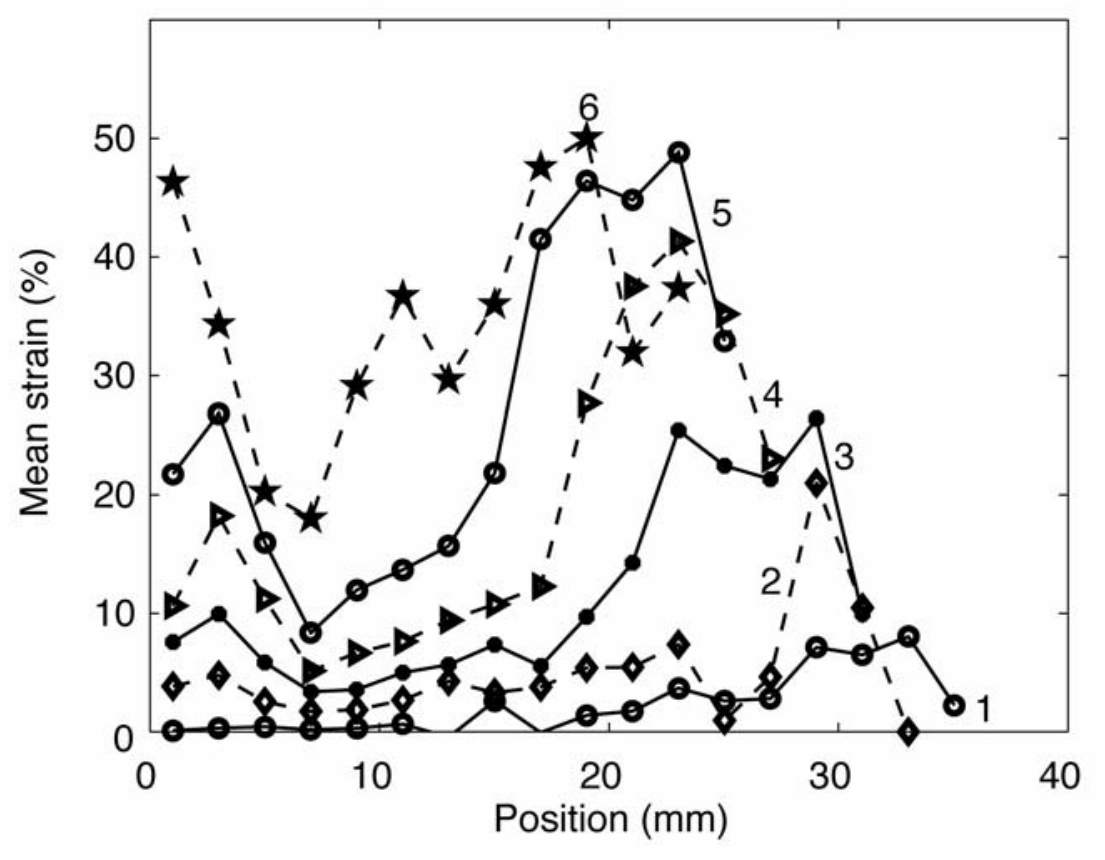

Figure 16. Change of the mean longitudinal strain in the specimen impacted at a) $47 \mathrm{~m} / \mathrm{s}$

b) $56 \mathrm{~m} / \mathrm{s}$ (solid line: even numbers of images, dashed line: odd numbers of images) 
The time history of the mean longitudinal strain is given in Figure 16. For an impact velocity of $47 \mathrm{~m} / \mathrm{s}$, the strain field is not homogeneous for the first image. The strain field shows that the specimen can be divided into two parts. One part on the right hand side in contact with the striker, which is immediately compacted at $20 \%$ and increases up to $40 \%$. The other part on the left hand side, in contact with the bar, remains compacted at levels less than $10 \%$.

It is clearly observed that the boundary between these two parts is moving. The same conclusions are drawn for the $56-\mathrm{m} / \mathrm{s}$ impact. This means that a shock front propagates within the specimen. The position of the shock front in the specimen height is calculated by taking the bar face as the reference. The position of the discontinuity is determined arbitrarily by the beginning of the sharp increase of the strain profile in Figure 16. Since the capture time of each image is known, the shock front speed is determined (Figure 17). It appears that the position is quasi-linear with time, which means a constant shock velocity. For the $47 \mathrm{~m} / \mathrm{s}$ impact velocity, the value is estimated at $70 \mathrm{~m} / \mathrm{s}$. Conversely, for the $56 \mathrm{~m} / \mathrm{s}$ impact velocity, the value is estimated at $87 \mathrm{~m} / \mathrm{s}$.






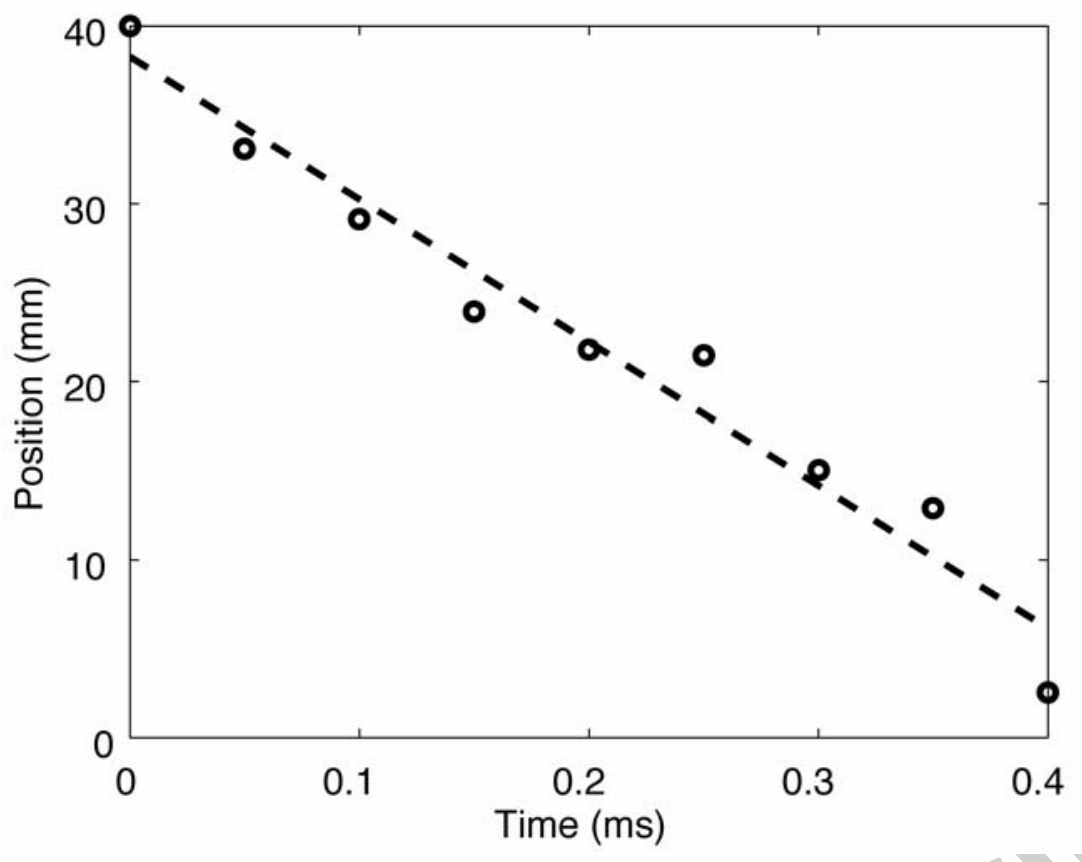

Figure 17. Position of the shock front with time for two impact velocities:

$$
47 \mathrm{~m} / \mathrm{s}(\mathrm{a}) \text { and } 56 \mathrm{~m} / \mathrm{s}(\mathrm{b})
$$

\section{Summary}

The present paper reports a new testing concept to investigate shock enhancement of cellular materials. The key points of this testing method are the following:

- use of a $60-\mathrm{mm}$ diameter Nylon split Hopkinson bar, which allows for accurate measurements by eliminating possible scatter due to small ratios of specimen size to cell size, or due to low signal / noise ratio because of a poor impedance ratio between the foam-like material and the (metallic) pressure bar;

- use of two testing configurations to measure the stress history behind and ahead of the shock front.

Reported tests provide an original experimental proof of the existence of shock front propagation within the specimen, by measuring the shock stress jump as well as the shock front velocity. It also shows that shock enhancement exists at rather moderate impact velocities around $50 \mathrm{~m} / \mathrm{s}$.

Systematic experiments are carried out for various cellular materials such as aluminium honeycombs, Cymat and Alporas aluminium foams as well as nickel hollow sphere 
agglomerates. For Alporas foams and nickel hollow spheres, the shock stress jump is experimentally observed and the shock front velocity is measured.

The shock front (i.e., strain jump) propagation in an Alporas foam is directly measured using digital image correlation applied to images captured with a high-speed camera. It provides another experimental proof of the existence of a shock front at this low impact speed $(56 \mathrm{~m} / \mathrm{s})$ and enables for a quantitative evaluation of the shock front velocity. Theoretical and numerical analyses of shock enhancement will be presented in a companion paper. 


\section{References}

Besnard, G., Hild, F., Roux, S., 2006, "Finite-element" displacement fields analysis from digital images: Application to Portevin-Le Châtelier bands, Exp. Mech. 46: 789-803.

Dannemann, K.A., Lankford, J., 2000, High strain rate compression of closed-cell aluminium foams, Mater. Sci. \& Engng., A293, 157-164.

Davies, R.M., 1948, A critical study of Hopkinson pressure bar, Phil. Trans. Roy. Soc., A240, 375-457.

Deshpande, V.S., Fleck, N.A, 2000, High strain rate compressive behaviour of aluminium, Int. J. Impact. Engng., 24, 277-298.

Gibson, L.J, Ashby, M.F, 1988. Cellular Solids, Pergamon Press.

Goldsmith, W., Sackman, J. L., 1992, An experimental study of energy absorption in impact on sandwich plates, Int. J. Impact Engng., 12 (2), 241-262.

Han, F., Cheng, H., Li, Z., Wang, Q., 2005, The strain rate effect of an open cell aluminium foam, Metal. \& Mater. Trans., 36A, 645-650.

Hild, F., Roux, S., 2006, Digital image correlation: from displacement measurement to identification of elastic properties, a review, Strain, 42, 69-80.

Hopkinson, B., 1914, A method of measuring the pressure in the deformation of high explosives or by the impact of bullets, Phil. Trans. Roy. Soc., A213, 437-452.

Karagiozova, D., Yu, T.X., Gao, Z.Y., 2006, Modelling of MHS cellular solid in large strains, Int. J. Mech. Sci 48, 1273-1286

Klintworth, J.W., Stronge, W.J, 1988, Elasto-plastic yield limits and deformation laws for transversely crushed honeycombs, Int. J. Mech. Sci., 30 (3-4), 273-292.

Kolsky, H., 1949, An investigation of the mechanical properties of materials at very high rates of loading, Proc. Phys. Soc., B62, 676-700.

Lopatnikov, S.L., Gama, B.A., Haque, Md. J., Krauthauser, C., Gillespie, J.W., Guden, M., Hall, I.W., 2003, Dynamics of metal foam deformation during Taylor cylinderHopkinson impact experiment, Composite structure, 61, 61-71.

Lopatnikov, S.L., Gama, B.A., Haque, Md. J., Krauthauser, C., Gillespie, J.W., Guden, M., 2004, High-velocity plate impact of metal foams, Int. J. Impact Engng., 30, 421-445.

Mukai, T; Kanahashi, H., Miyoshi, T., Mabuchi, M., Nieh, T.G., Higashi, K., 1999. Experimental study of energy absorption in a closed cell aluminium foam under dynamic loading, Scripta Materialia, 40, 921-927. 
Nemat-Nasser, S., Kang, W.J., McGee, J.D., Guo, W.G., Issac J.B., Experimental investigation of energy absorption characteristics of component of sandwich structures. Int. J. Impact Engng., 34, 1119-1146.

Reid, S.R., Peng, C., 1997, Dynamic uniaxial crushing of wood, Int. J. Impact Engng., 19, 531-570.

Radford, D.D, Deshpande, V.S., Fleck, N.A., 2005, The use of metal foam projectile to simulate shock loading on a structure, Int. J. Impact Engng., 31, 1152-1171.

Tan, P.J., Harrigan, J.J., Reid, S.R., 2002, Inertia effects in uniaxial dynamic compression of a closed cell aluminium alloy foam, Material Science \& Technology, 18, 480-488.

Tan, P.J., Reid, S.R., Harrigan, J.J., Zou, Z., Li, S., 2005, Dynamic compressive strength properties of aluminium foams. Part I-experimental data and observations, , J. Mech. Phys. Solids, 53, 2174-2205

Wu, E., Jiang, W.S., 1997, Axial crush of metallic honeycombs, Int. J. Impact Engng., 19, 439-456.

Zhao, H., Gary, G., 1995, A three dimensional analytical solution of longitudinal wave propagation in an infinite linear viscoelastic cylindrical bar, Application to experimental techniques, J. Mech. Phys. Solids, 43 (8), 1335-1348.

Zhao, H., Gary, G., 1996, On the use of SHPB techniques to determine the dynamic behaviour of materials in the range of small strains, Int. J. Solids Struct., 33(23), 33633375 .

Zhao, H., Gary, G., 1998, Crushing behaviours of aluminium honeycomb under impact loading, Int. J. Impact Engng, 21, 827-836.

Zhao, H., Abdennadher, S., 2004, On the strength enhancement under impact loading of square tubes made from rate insensitive metals, Int. J. Solid Struct., 41, 6677-6697.

Zhao, H., Nasri, I., Abdennadher, S., 2005, An experimental study on the behaviour under impact loading of metallic cellular materials, Int. J. Mech. Sci., 47, 757-774.

Zienkievicz, O.C., Taylor, R.L., 1989, The Finite Element Method. McGraw-Hill, London (UK). 


\section{Appendix. Shock enhancement calculation with the RPRL}

\section{model}

Assuming that a foam-like material initially at rest is loaded by a shock front (shock front speed $U$ and velocity behind the shock front $\mathrm{V}_{\text {impact }}$ ) as shown in Figure 2, the two particle velocities across the shock front read

$$
\begin{aligned}
& v_{0}=0 \\
& v_{1}=V_{\text {impact }}
\end{aligned}
$$

Using the RPRL model, the density behind the shock wave is given by

$$
\rho_{1}=\frac{\rho_{0}}{1-\varepsilon_{\text {lock }}}
$$

where $\varepsilon_{\text {lock }}$ denotes the locking strain. The mass conservation (Eqn. (1)) leads to

$$
\rho_{0} U=\rho_{1}\left(U-V_{\text {impact }}\right)
$$

It provides an explicit expression for the shock wave speed $U$

$$
U=\frac{V_{\text {impact }}}{\varepsilon_{\text {lock }}}
$$

Shock enhancement is then obtained by using Eqn. (2)

$$
\sigma_{1}-\sigma_{0}=\frac{\rho_{0} V_{\text {impact }}^{2}}{\varepsilon_{\text {lock }}}
$$

